\title{
Menentukan Tingkat Kepuasan Pelanggan \\ PDAM Payakumbuh Setelah Pembangunan \\ Water Treatment Plant Batang Agam
}

\author{
Harfa Sakri ${ }^{1}$,Junaidi ${ }^{2}$,Bambang Istijono ${ }^{3}$ \\ Fakultas Teknik, Universitas Andalas ${ }^{1}$, Dosen Fakultas Teknik, Universitas Andalas ${ }^{2,2}$ \\ email : harfa1101849@gmail.com ${ }^{1}$,junaidi@eng.unand.ad.id ${ }^{2}$, bistijono@gmail.com ${ }^{3}$ \\ DOI: http://dx.doi.org/10.31869/rtj.v3i2.1905
}

\begin{abstract}
The aim of this research was to measure the level of customer satisfaction with the services of Payakumbuh PDAM after the construction of the Batang Agam Water Treatment Plant as one source of raw water. The result of this research explain that service of Payakumbuh PDAM after construction of Batang Agam Water Treatment Plant which analyzed using the Importance Performance Analysis method. There are 7 question attributes that become measurement points. In the first and second questions attribute about the smooth running of water at the peak hours of morning and evening whose value was in quadrant A where Payakumbuh PDAM should make an effort to improve customer satisfaction which means that these quality attributes need to be improved and improved continuously so that the quality attribute performance regarding smoothness at the peak hours in this quadrant increases and customer satisfaction can be achieved. Besides that, the attributes about water clarity, colorless water, tastes fresh, odorless water and normal temperature have reached quadrant $B$ or known achievement priority. This position shows the quality of raw water product from Batang Agam Water Treatment Plant has been successfully carried out by Payakumbuh PDAM, so that, it must be maintained.
\end{abstract}

Keywords: Batang Agam WTP, Customer Satisfaction, Importance Performace Analysis (IPA)

\section{PENDAHULUAN}

Kota Payakumbuh merupakan salah satu kota yang ada di Provinsi Sumatera Barat. Kota Payakumbuh ini merupakan pemekaran dari Kabupaten Lima Puluh Kota, sehingga Kota Payakumbuh ini berada di tengah-tengah kawasan Kabupaten Lima Puluh Kota.

Pengelolaan serta pendistribusian air bersih di Indonesia dikelola oleh negara. Perusahaan Daerah Air Minum (PDAM) merupakan perusahaan yang diberi wewenang oleh negara dalam mengelola sumber daya air dan pemanfaatannya yang bisa dikonsumsi oleh masyarakat umum. PDAM ini tersebar di seluruh Indonesia dari Provinsi sampai Kabupaten dan Kota untuk memenuhi kebutuhan akan air bersih yang salah satunya adalah PDAM Kota Payakumbuh.

PDAM Kota Payakumbuh mempunyai 3 unit sumber air baku, yang berada pada lereng Gunung Sago wilayah Kabupaten Lima Puluh Kota, yaitu Batang Tabit, Sungai Dareh dan Sikamuruncing. Air yang tersedia pada 3 unit sumber air baku tersebut tidak diambil secara keseluruhan oleh PDAM karena banyak keperluan lain disekitar lokasi sumber air misalnya keperluan untuk pertanian, perikanan, peternakan, rumah tangga serta wisata. Ketiga sumber air baku tersebut terletak di kawasan wilayah administrasi Kabupaten Lima Puluh Kota sebagaimana yang terlihat pada gambar 1 .

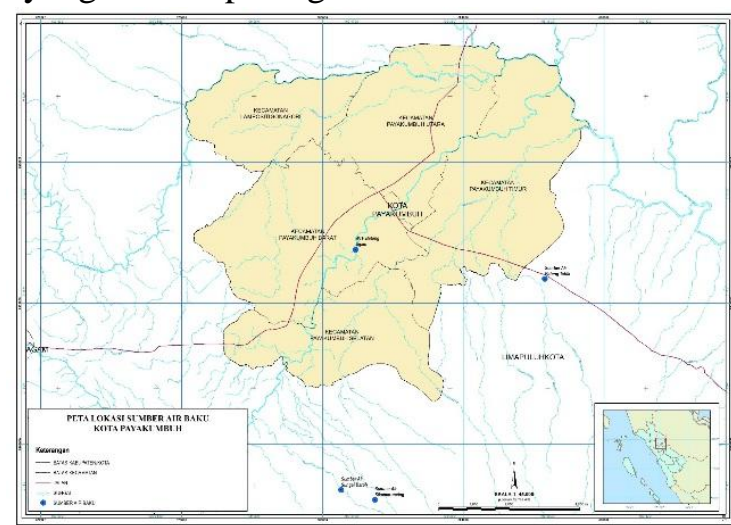

Gambar 1. Wilayah Kota Payakumbuh dan lokasi Sumber Air Baku PDAM Kota Paykumbuh.

Badan Pemeriksa Keuangan (BPK) mengusulkan pemerintah Kota Payakumbuh agar melaksanakan Proyek Pengembangan Sistem Penyedia Air Minum (PSPAM) Untuk Pembangunan Water Treatment Plant (WTP) di Batang Agam Kota Payakumbuh yang merupakan pengolahan berteknologi tinggi aliran sungai Batang Agam menjadi sumber air bersih dan layak untuk dikonsumsi dan 
didistribusikan ke masyarakat. Bangunan WTP Batang Agam ini akan menjadi salah satu sumber air baku di kawasan Kota Payakumbuh.

Pada tahun 2009 Ari Agung Nugroho melakukan penelitian dengan judul Analisis Tingkat Kepuasan Pelanggan Perusahaan Daerah Air Minum (PDAM) Tirta Pakuan Kota Bogor Di Kecamatan Bogor Timur menyimpulkan bahwa Evaluasi kepuasan pelanggan sangat penting dilakukan sebagai salah satu upaya untuk melihat tingkat kinerja PDAM Tirta Pakuan Kota Bogor, Analisis Importance Performance Analyse (IPA) dilakukan terhadap mutu produk dan kualitas pelayanan yang terbagi dalam 4 kuadran, yaitu kuadran A (dinilai sangat penting tapi kinerja belum memuaskan), kuadran B (dinilai sangat penting dan sudah memuaskan), kuadran $\mathrm{C}$ (dinilai kurang penting dan kurang memuaskan), dan kuadran D (dinilai kurang penting tetapi sangat memuaskan). Berdasarkan beberapa penelitian, untuk menentukan Tingkat Kepuasan Pelanggan PDAM Kota Payakumbuh Setelah Pembangunan Water Treatment Plant Batang Agam dilakukan penelitian dengan analisis menggunakan metoda Importance Performance Analyse (IPA).

\section{METODOLOGI PENELITIAN}

Penelitian ini dilakukan pada pelanggan PDAM Kota Payakumbuh yang sudah dialiri air WTP Batang Agam dalam tiga bagian yakni pengumpulan data, pengolahan data dan hasil penelitian berupa kesimpulan dan saran.

\section{Metoda Pengumpulan Data}

Metoda pengumpulan data adalah cara mengumpulkan data-data yang diperlukan dalam sebuah penelitian. Pada penelitian ini menggunakan data primer dan data sekunder. Data primer adalah data yang diperoleh dari lapangan dengan menyebarkan angket atau observasi langsung ke lapangan yang berkaitan dengan kepuasan pelangan terhadap layanan kualitas produk Water Treatment Plant Batang Agam Kota Payakumbuh yang terdiri dari beberapa data yakninya Data kerakterstik pelanggan yang meliputi jenis kelamin, umur, pendidikan terakhir, pekerjaan serta status kepemilikan tempat tinggal serta data tingkat kepentingan dan tingkat kepuasan pelanggan terhadap kualitas produk Water Treatment Plant Batang Agam Kota Payakumbuh yang meliputi kelancaran pada jam puncak pagi dan sore, kejernihan air, air tidak berwarna, air tidak berasa, air tidak berbau dan temperatur air normal.

Data sekunder merupakan data pendukung yang bersumber dari literatur maupun referensi-referensi yang ada. Data sekunder yang dibutuhkan antara lain data jumlah dan kategori pelanggan PDAM Kota Payakumbuh, data jumlah dan kategori pelanggan PDAM yang sudah dialiri WTP Batang Agam.

\section{Pengolahan Data}

Langkah-langkah yang dilakukan dalam pengolahan data sebagai berikut :

a. Melakukan pengelompokan konsumen sesuai kategori pemakaian PDAM.

b. Melakukan uji coba penelitian dan menentukan validitas releabilitas kuesioner.

\section{Populasi}

Menurut Sugiyono (2007: 80) "Populasi adalah wilayah generalisasi yang terdiri atas objek atau subjek yang mempunyai kualitas dan karakteristik tertentu yang ditetapkan oleh peneliti untuk dipelajari dan kemudian ditarik kesimpulannya. Populasi adalah keseluruhan subjek penelitian. Populasi dalam penelitian ini adalah kosumen pada kelurahan yang sudah dialiri air bersih yang bersumer dari WTP Batang Agam sebagaimana dijelaskan pada tabel 1.

Tabel 1. Pelanggan WTP Kota Payakumbuh Sejak April 2019

\begin{tabular}{|l|l|l|}
\hline No. & Kelurahan & $\begin{array}{l}\text { Jumlah } \\
\text { Pelanggan }\end{array}$ \\
\hline 1. & Padang Tangah & 165 \\
\hline 2. & Parak Batuang & 133 \\
\hline 3. & Parik Rantang & 781 \\
\hline 4. & Balai Nan Duo & 150 \\
\hline 5. & Tanjuang Gadang & 864 \\
\hline & Jumlah & $\mathbf{2 0 9 3}$ \\
\hline
\end{tabular}

Sumber : PDAM Kota Payakumbuh 2019

Sampel

Sampel adalah bagian dari populasi yang akan diteliti. Menurut Sugiyono (2006: 81) "Sampel adalah bagian dari jumlah dan karakteristik yang dimiliki oleh populasi 
tersebut". Pada penelitian ini jumlah sampel yang dipilih dengan menggunakan teknik Probability Random Sampling yaitu teknik pengambilan sampel yang memberikan peluang yang sama bagi setiap unsur (anggota) populasi untuk dipilih menjadi anggota sampel. Untuk menentukan jumlah responden pengisian kuesioner ditentukan dengan menggunakan rumus Slovin sebagai berikut :

$n=\frac{N}{1+N e^{2}}$

Keterangan:

$\mathrm{n}=$ Jumlah sampel (responden) yang diperlukan

$\mathrm{N}=$ Jumlah populasi

$\mathrm{e}=$ Batas toleransi kesalahan (error tolerance) $5 \%$

Menurut data dari PDAM Kota payakumbuh kelurahan yang sudah dialiri oleh WTP Batang Agam berjumlah 2408 titik di lima kelurahan. Sehingga diperoleh hasil perhitungan sebagai berikut :

$n=\frac{2093}{1+2093 \times 0,05^{2}}$

$n=\frac{2093}{6,23}$

$n=335,95 \approx 336$ responden (dibulatkan)

Hasil perhitungan penentuan sampel e $=5 \%$ adalah 336 titik responden.

Dari perhitungan diatas, dapat diperoleh jumlah sampel sebanyak 336 titik responden. Kemudian dilakukan perhitungan untuk masing-masing jumlah sampel pelanggan dari lima kelurahan, yakni sebagai berikut :

a. Sampel untuk kelurahan Padang Tangah $n=\frac{165}{2093} \times 336$

$$
n=26,48 \approx 26 \text { responden (dibulatkan) }
$$

b. Sampel untuk kelurahan Parak Batuang $n=\frac{133}{2093} \times 336$

$$
n=21,35 \approx 21 \text { responden (dibulatkan) }
$$

c. Sampel untuk kelurahan Parik Rantang $n=\frac{781}{2093} \times 336$

$$
\begin{aligned}
& n=125,37 \approx 125 \text { responden } \\
& \text { (dibulatkan) }
\end{aligned}
$$

d. Sampel untuk kelurahan Balai Nan Duo $n=\frac{150}{2093} \times 336$

$n=24,08 \approx 25$ responden (dibulatkan)

e. Sampel untuk kelurahan Tanjuang Gadang

$n=\frac{864}{2093} \times 336$

$$
n=138,7 \approx 139 \text { responden (dibulatkan) }
$$

Angket adalah daftar pertanyaan yang tersusun dengan baik yang digunakan untuk alat pengumpulan data melalui survei. Angket harus sesuai dengan masalah yang diteliti, oleh karena itu sebelum menyusun angket, masalah penelitian harus dirumuskan dengan jelas. Jenis data yang dapat dikumpulkan menggunakan angket bisa kualitatif maupun kuantitatif. Pada penelitian ini akan difokuskan pada penilaian kepuasan pelanggan terhadap kualitas produk air PDAM Kota Payakumbuh setelah pembangunan Water Treatmen Plant Batang Agam. Pertanyaan pada angket akan dibagi menjadi dua bagian, yaitu :
Bagian A : Karakteristik Responden
Bagian B : Dimensi Kepuasan terhadap kualitas Produk

Untuk penghitungan angket ini menggunakan metode skala likert. Skala likert digunakan untuk mengukur sikap, pendapat dan persepsi seseorang atau sekelompok orang tentang fenomena sosial (Sugiono : 2015). Jawaban setiap insrumen Pada skala likert digunakan pembobotan skala 1 sampai dengan 5, angka 1 berarti nilai pelayanan tidak puas sampai dengan angka 5 yang berarti nilai pelayanan sangat puas. Sebagaimana dijelaskan sebagai berikut :

TP : TIDAK PUAS / PENTING Skor 1

KP : KURANG PUAS / PENTING Skor 2

$\mathrm{N}$ : NETRALSkor 3

$\mathrm{P}$ : PUAS / PENTING Skor 4

SP : SANGAT PUAS / PENTING Skor 5 
Menganalisis hasil dari angket dengan medoda Importance Performance Analyse (IPA)

Metoda Importance Performance Analyse (IPA) diperkenalkan oleh Martilla dan James pada tahun 1977 dengan tujuan untuk mengukur hubungan antara persepsi konsumen dan prioritas peningkatan kualitas produk/jasa yang dikenal sebagai quadrant analysis (Brandt, 2015). Angket yang sudah diisi oleh responden akan dihitung dengan menggunakan Excel dan akan dijelaskan dan dibagi menjadi empat bagian ke dalam diagram kartesius yang menunjukkan bahwa kuadra I adalah prioritas utama, kuadran II adalah pertahankan, kuadran III adalah prioritas rendah, dan kuadran IV adalah berlebihan.

\section{HASIL DAN PEMBAHASAN}

\section{Karekteristik Responden}

Data karakteristik responden merupakan data sebaran responden yang terdiri dari jenis kelamin, umur, pendidikan, pekerjaan, status kepemilikan, sebaran lama pemakaian PDAM, uji kepuasan secara umum dan jenis pemakaian yang akan dijabarkan dalam tabel 2.

Tabel 2. Rekap Karakteristik Responden

\begin{tabular}{|c|c|c|c|}
\hline No & Urian & Jumlah & $\begin{array}{l}\text { Presentase } \\
\%\end{array}$ \\
\hline 1 & \multicolumn{3}{|l|}{ Jenis kelamin } \\
\hline & - Laki-laki & 116 & 34,52 \\
\hline & - Perempuan & 220 & 65,48 \\
\hline & Jumlah & 336 & 100 \\
\hline \multirow[t]{7}{*}{2} & \multicolumn{3}{|l|}{ Umur } \\
\hline & $-<17$ th & 52 & 15,48 \\
\hline & $-17-25$ th & 48 & 14,29 \\
\hline & $-25-40$ th & 90 & 26,79 \\
\hline & $-40-60$ th & 100 & 29,76 \\
\hline & $->60$ th & 46 & 13,69 \\
\hline & Jumlah & 336 & 100 \\
\hline \multirow[t]{7}{*}{3} & \multicolumn{3}{|c|}{ Pendidikan Terakhir } \\
\hline & $-\mathrm{SD}$ & 28 & 8,33 \\
\hline & - SMP & 96 & 28,57 \\
\hline & - SMA & 133 & 39,58 \\
\hline & - D3 & 15 & 4,46 \\
\hline & $-\mathrm{S} 1$ & 58 & 17,26 \\
\hline & $-\mathrm{S} 2$ & 6 & 1,79 \\
\hline
\end{tabular}

\begin{tabular}{|c|c|c|c|}
\hline & $-\mathrm{S} 3$ & 0 & 0,00 \\
\hline & Jumlah & 336 & 100,00 \\
\hline 4 & \multicolumn{3}{|l|}{ Pekerjaan } \\
\hline & - Pelajar & 82 & 24,4 \\
\hline & - PNS/TNI/Polri & 15 & 4,5 \\
\hline & - Wirausaha & 78 & 23,2 \\
\hline & - Guru/Dosen & 23 & 6,8 \\
\hline & - Swasta & 24 & 7,1 \\
\hline & - Lain-lain & 114 & 33,9 \\
\hline & Jumlah & 336 & 100 \\
\hline 5 & \multicolumn{3}{|c|}{ Status Kepemilikan Rumah } \\
\hline & - Pribadi & 259 & 77,08 \\
\hline & - Kost & 5 & 1,49 \\
\hline & - Kontrak & 50 & 14,88 \\
\hline & - Lainnya & 22 & 6,55 \\
\hline & Jumlah & 336 & 100 \\
\hline \multirow[t]{7}{*}{6} & \multicolumn{3}{|c|}{ Durasi Penggunaan PDAM } \\
\hline & - 1 Tahun & 20 & 5,95 \\
\hline & -2 Tahun & 20 & 5,95 \\
\hline & - 3 Tahun & 31 & 9,23 \\
\hline & - 4 Tahun & 25 & 7,44 \\
\hline & $->5$ Tahun & 240 & 71,43 \\
\hline & Jumlah & 336 & 100 \\
\hline \multirow[t]{5}{*}{7} & \multicolumn{3}{|c|}{ Uji Kepuasan Secara Umum } \\
\hline & - Sangat Puas & 94 & 27,98 \\
\hline & - Puas & 217 & 64,58 \\
\hline & - Tidak Puas & 25 & 7,44 \\
\hline & Jumlah & 336 & 100 \\
\hline 8 & \multicolumn{3}{|l|}{ Jenis Pemakaian } \\
\hline & - RT A & 206 & 61,31 \\
\hline & - RT B & 51 & 15,18 \\
\hline & - RT C & 16 & 4,76 \\
\hline & - NKM & 54 & 16,07 \\
\hline & $-\mathrm{NB}$ & 9 & 2,68 \\
\hline & $-\mathrm{SU}$ & 0 & 0,00 \\
\hline & $-\mathrm{SK}$ & 0 & 0,00 \\
\hline & - IP & 0 & 0,00 \\
\hline $\mathbf{J u}$ & & 336 & 100 \\
\hline
\end{tabular}

Sumber : Pengolahan data 2019

Pengkategorian kelompok pelanggan air bersih PDAM Kota Payakumbuh adalah sebagai berikut, Rumah tangga A (RT A) 
merupakan rumah sederhana atau rumah tangga dengan tipe $<36 \mathrm{~m}^{2}$ dengan jumlah pengguna minimal 4 orang/hari. Rumah tangga B (RT B) adalah rumah menengah rumah tangga dengan tipe $\geq 36 \mathrm{~m}^{2}$ dengan jumlah pengguna minimal 4 orang/hari. Rumah tangga C (RT C) adalah rumah mewah atau rumah tangga dengan kegiatan usaha kecil

. Kelompok Niaga Kecil Menengah (NKM) Seperti BUMD, praktek dokter (umum, spesialis, gigi, hewan), kantor profesi (notaris, PPAT, pengacara, penasehat hukum, konsultan publik, psikolog dan lain-lain. Kelompok Niaga Besar (NB) Seperti BUMN, kantor instansi swasta (bank asuransi, koperasi, lembaga pembiayaan/leasing, developer, pemasaran, distributor), plaza, swalayan, mall, mega mall, super mall, lembaga Pendidikan dan lain-lain dengan jumlah pengguna minimal 10 orang/hari.

Kelompok Sosial Umum (SU) Seperti KM/WC umum non komersil, terminal air dengan jumlah pengguna minimal 50 orang/hari. Kelompok Sosial Khusus (SK) Seperti panti asuhan, yayasan sosial, tempat ibadah dengan jumlah pengguna minimal 50 orang/hari. Instansi Pemerintah (IP) Seperti Sarana milik instansi pemerintah, sarana milik instansi kepolisian, sarana milik instansi TNI dengan jumlah pengguna minimal 50 orang/hari.

\section{Tingkat Kepentingan dan Kepuasan Pelanggan Terhadap Kualitas Layanan PDAM Setelah Pembangunan Water Treatmen Palnt Batang Agam.}

Dari ketujuh atribut pertanyaan mengenai kualitas layanan produk PDAM Kota payakumbuh setelah pembangunan Water Treatmen Plant Batang Agam Kota payakumbuh, maka didapatkan rata-rata tingkat kepentingan dan tingkat kepuasan pelanggan yang dapat kita jabarkan dengan metode Importance Performance Analice untuk menentukan atribut pertanyaan ini berada pada kuadran berapa.

Untuk mendapatkan nilai rata-rata tingkat kepentingan dan tingkat kepuasan pelanggan untuk setiap soal dihitung dengan menggunakan rumus sebagai berikut :

jawaban rata-rata $=\sum \mathrm{A}: \mathrm{B}$

$\mathrm{A}=\mathrm{J}$ awaban responden
$\mathrm{B}=$ Jumlah Responden

Jumlah jawaban responden pada tingkat kepentingan dengan jumlah responden 336 orang.

Untuk nilai rata-rata jawaban resonden dijelaskan pada tabel 3.

Tabel 3. Rekap tingkat kepentingan dan kepuasan pelanggan terhadap kualitas layanan PDAM.

\begin{tabular}{clcc}
\hline NO. & \multicolumn{1}{c}{ Atribut Kualitas layanan PDAM } & KEPENTINGAN & KEPUASAN \\
\hline 1 & Lancar pada jam puncak pagi $(05.00-08.00)$ & 4,98 & 3,75 \\
\hline 2 & Lancar pada jam puncak sore $(17.00-20.00)$ & 4,98 & 3,62 \\
\hline 3 & Airj jernih dan tidak keruh & 4,98 & 4,73 \\
\hline 4 & air tidak berwarna & 4,98 & 4,76 \\
\hline $\mathbf{5}$ & air rasanya tawar (tidak Berasa) & 4,98 & 4,72 \\
\hline $\mathbf{6}$ & air tidak berbau & 4,98 & 4,66 \\
\hline $\mathbf{7}$ & temperatur air normal & 4,98 & 4,73 \\
\hline & RATA-RATA & 4,98 & 4,42
\end{tabular}

Sumber : Pengolahan 2019

Nilai rata-rata keseluruhan ini akan menjadi sumbu $x$ dan sumbu y pada diagram kartesius IPA yakninya faktor kepuasan sebagai sumbu $\mathrm{x}$ dan faktor kepentingan sebagai sumbu Y.

Importance Performance Analyse (IPA) Kualitas produk PDAM Kota Payakumbuh setelah Pembangunan Water Treatmen Plant Batang Agam

Diagram kartesius pada Importance Performance Analyse merupakan suatu bangun yang dibagi atas empat bagian yang dibatasi oleh dua buah garis yang berpotongan tegak lurus pada titik-titik (Supranto, 2006). Merupakan nilai rata-rata dari tingkat kepentingan dan tingkat kepuasan pelanggan terhadap seluruh atribut pertanyaan.

Importance Performance Analyse dibutuhkan untuk melihat kedudukan tujuh atribut kualitas produk yang diperoleh berdasarkan tingkat kepentingan dan tingkat kinerja dari 336 pelanggan PDAM Kota Payakumbuh yang sudah di aliri sumber air baku Water Treatmen Palnt Batang Agam Kota Payakumbuh. Atribut mutu kualitas produk.

Nilai rata-rata untuk tingkat kepentingan mutu kualitas produk adalah sebesar 4,98 dan tingkat kepuasan mutu kualitas produk adalah 4,42. Seluruh atribut mutu produk yang tersebar di empat bagian yaitu kuadran A 
(prioritas utama), kuadran B (pertahankan prestasi), kuadran $\mathrm{C}$ (prioritas rendah) dan kuadran D (berlebihan) sebagaimana dijelaskan pada gambar 2 .

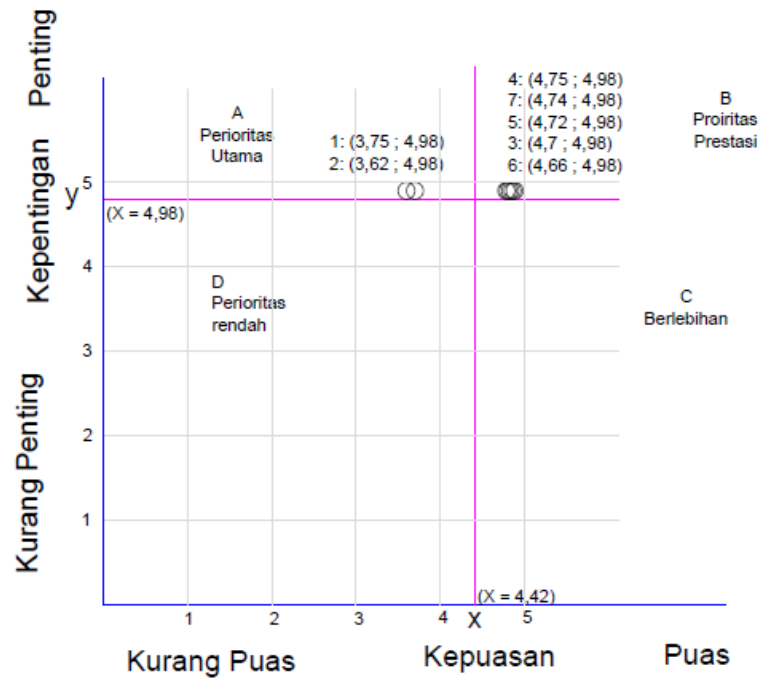

Gambar 2. Diagram kartesius Importance Performance Analyse

Sumber : Pengolahan data 2019

Berdsarkan gambar 2 dapat kita baca bahwa atribut nomor 1 dan 2 berada pada kuadran A yang artinya posisi ini menunjukkan faktor yang mempengaruhi kepuasan pelanggan terhadap kelancaran air pada jam-jam puncak yaitu Lancar pada jam puncak pagi $(05.00$ - 08.00) dan jam puncak sore (17.00-20.00) . Atribut-atribut kualitas ini dianggap sangat penting oleh pelanggan belum dilaksanakan oleh PDAM Kota Payakumbuh sesuai dengan keinginan pelanggan, sehingga pelanggan menuntut adanya evaluasi mengenai kualitas air dari Water Treatmen Plant Batang Agam tentang kelancaran pada saat jam-jam puncak. PDAM Kota Payakumbuh hendaknya melakukan usaha untuk meningkatkan pelayanan.

Terdapat beberapa hal yang dapat dilakukan dalam mengatasi permasalahan ini adalah sebagai berikut :

a. Pemerintah dapat mengatur waktu pemakaian.

b. Mengusulkan kepada pelanggan agar menggunakan bak penampung sementara yang dapat dimanfaatkan sebagai penyimpanan air sementara yang dapat diisi diluar jam-jam puncak.

c. Untuk pelanggan yang kurang mampu pemerintah sebaiknya dapat memberikan bantuan untuk pengadaan bak penampung sementara di setiap rumah.

Dengan memperhatikan kepuasan pelanggan sehingga performance butir pertanyaa kualitas yang ada dalam kuadran ini akan meningkat dan kepuasan pelangganpun dapat tercapai. Disamping itu atribut no 3,4,5,6 dan 7 sudah mencapai kuadran B yaitu pada posisi prioritas prestasi, posisi ini menunjukkan unsur kualitas produk air baku dari WTP Batang Agam yang telah berhasil dilaksanakan dengan baik oleh PDAM Kota Payakumbuh, untuk itu wajib dipertahankan. Dianggap sangat penting dan sangat memuaskan. Hal ini menuntut PDAM Kota Payakumbuh untuk dapat mempertahankan posisinya.

\section{PENUTUP}

\section{Simpulan}

Berdasarkan penelitian yang dilakukan, hasil penelitian ini menjelaskan bahwa Tingkat kepuasan pelanggan terhadap pelayanan PDAM Kota Payakumbuh Setelah Pembangunan Water Treatment Plant Batang Agam. Ada 7 atribut pertanyaan yang menjadi poin pengukuran dan pada atribut pertanyaan pertama dan kedua mengenai kelancaran air pada jam-jam puncak pagi dan sore yang nilainya berada pada kuadran A dimana PDAM Kota Payakumbuh sebaiknya melakukan usaha untuk meningkatkan kepuasan pelanggan yang berarti pula bahwa butir pertanyaan mengenai kualitas ini perlu diperbaiki dan ditingkatkan secara terusmenerus sehingga performance butir pertanyaan mengenai kualitas mengenai kelancaran pada jam-jam puncak yang ada dalam kuadran ini akan meningkat dan kepuasan pelangganpun dapat dicapai.

Disamping itu atribut tentang kejernihan air, air tidak berwarna, rasanya tawar, Air tidak berbau serta temperatur yang normal sudah mencapai kuadran B yaitunya prioritas prestasi Posisi ini menunjukkan unsur kualitas produk air baku dari Water Treatmen Plant Batang Agam yang telah berhasil dilaksanakan oleh PDAM Kota Payakumbuh, untuk itu wajib dipertahankan. Dianggap sangat penting dan memuaskan. Hal ini menuntut perusahaan untuk dapat mempertahankan posisinya. 


\section{Saran}

Penelitian ini juga dapat dikembangkan lebih luas lagi oloeh peneliti selanjutnya.

\section{DAFTAR PUSTAKA}

Agung N Ari, 2009. Analisis Tingkat Kepuasan Pelanggan Perusahaan Daerah Air Minum (PDAM) Tirta Pakuan Kota Bogor di Kecamatan Bogor Timur, Bogor : IPB

Asdak,Chay. 2002. Hidrologi dan pengolahan daerah aliran sungai. Gajah Mada University Press, Yogyakarta.

Br., Sri Harto. 2000. Hidrologi, TeoriMasalah-Penyelesaian. Yogyakarta: Nafiri Offset.

GeologiNesia, 2018, Pengertian, Fungsi, Sumber, dan Manfaatnya.htm=[20 mei 2019]

Islamy. Dalilul, 2014. Studi Kinerja Pelayanan Pdam Tirta Siak Berdasarkan Pendapat Pelanggan (Studi Kasus: PDAM TIRTA SIAK PEKANBARU), Jurnal Teknik PWKhttp://ejournals1.undip.ac.id/inde x.php/pwk.

Mardiansyah Wahyu, Pengukuran Kualitas Pelayanan Perusahaan Daerah Air Minum (Pdam) Kota Bekasi Berdasarkan Kepuasan Pelanggan, Universitas Guna Dharma.

Prabowo,S. 2017. Analisis Tingkat Kepentingan Dan Tingkat Kepuasan Unit Kerja Atas Kinerja Pegawai Pelaksana Kementerian Keuangan. Info Artha.

Soewarno. 1991. Hidrologi, Pengukuran Dan Pengolahan Data Aliran Sungai (Hidrometri). Nova.Jakarta.

Sugiyono.2015. Metode Penelitian Kuantitatif, Kualitatif dan R\&D, Alfabeta. Bandung 